\title{
Liminaalitilan käsite työn muutosten jäsentäjänä
}

\author{
$y$ \\ Liminaalitila on antropologiassa määritelty välitilaksi, \\ kynnyksellä olemiseksi. Liminaalisuus on nykypäivän \\ työelämälle ominainen piirre, joka voi näyttäytyä kaaoksena, \\ mutta myös uutta luovana muutosvaiheena.
}

TÄSSÄ ARTIK KELISSA hahmotellaan liminaalitilan käsitteen mahdollisuuksia työn ja työyhteisöjen tutkimuksessa. Artikkeli on luonteeltaan katsaus, joka luo yhteistä käsitteellistä pohjaa erilaisten työ- ja johtamisympäristöjen tutkimukselle. Omassa tutkimushankkeessamme ${ }^{1}$ pureudumme taidetyön, osuuskuntien, kansalaisjärjestötyön ja projektimuotoisen työn tutkimukseen. Näitä työympäristöjä luonnehtii työn organisoitumiseen, työntekijöihin ja työn luonteeseen liittyvät muutos- ja siirtymätilat. Menemättä syvemmälle yksittäisten työympäristöjen erityispiirteisiin keskitymme esittelemään liminaalitilan käsitettä ja pohtimaan sen käyttökelpoisuutta työelämän muutoksien ja muuttuvan johtajuuden tutkimisessa. Työn muutosta käsitellään sekä organisaatiotason muutosprosessien että yleisen työelämän, paradoksaalisiksi (ks. Julkunen 2008) luonnehdittujen muutostrendien näkökulmasta.
Jälkiteollisen yhteiskunnan työelämää on luonnehtinut siirtymä teollisesta tuotantotyöstä tietotyöhön ja palvelutuotantoon (Hautamäki 1996). Tietoverkkojen ja älypuhelinten monipuolinen käyttö on mahdollistanut työn tekemisen ajasta ja paikasta riippumatta ja synnyttänyt uudenlaisen verkostoyhteiskunnan (Castells 1996). Samalla rajanveto työn ja vapaa-ajan välille on tullut yhä hankalammaksi (Sennett 1998). Globaali talous toimii joustavasti; työtehtäviä siirretään nopeasti halvemman työvoiman maihin, ja yritysten lisääntyvä paine tuottaa voittoa osakkeenomistajille saattaa johtaa irtisanomisiin kannattavissakin yhtiöissä. Työelämäpuhe on muuttunut yhä enemmän kilpailukykypuheeksi. Uusien, taloudellisesti hyödynnettävien innovaatioiden kehittäminen on noussut niin yritystoiminnan kuin akateemisen tutkimuksenkin tavoitteeksi. Joustavuus, ketteryys, op- 
piminen ja luovuus ovat ilmiöitä, joita muuttuvassa työelämässä halutaan nähdä.

Samanaikaisesti suuret ikäluokat ovat siirtymässä eläkkeelle ja uudet Y-ja Z-sukupolvet ${ }^{2}$ ovat astuneet työmarkkinoille. Työelämä myös monikulttuuristuu maahanmuuton ja organisaatioiden kansainvälistymisen myötä. (Alasoini ym. 2012). Pätkätyöt ja määräaikaiset työsuhteet ovat lisääntymässä. Nuorten sukupolvien odotus työelämästä ei ole portaittain etenevä ura yhdessä organisaatiossa, vakituisessa työsuhteessa, vaan niin sanottu portfoliosukupolvi (Hoikkala \& Salasuo 2006) työskentelee vaihtuvissa tiimeissä ja verkostoissa rakentaen omaa yksilöllistä työidentiteettiään. Työelämän joustavuuden, kompleksisuuden, yksilöllistymisen ja monimuotoistumisen lisääntyminen tarjoaa toisaalta uudenlaisia mahdollisuuksia, mutta voi johtaa työelämän huonontumiseen ja kaaostumiseen. Liminaalitilan käsite kuvaa vanhan ja uuden välissä olemista, jossa uuden mahdollistava kaaos ja epävarmuus yhdistyvät esimerkiksi rituaalisen käyttäytymisen tuomaan turvallisuuteen. Työn muutosten pyörteissä on syytä pysähtyä pohtimaan välitilan ja liitoskohtien mahdollisuuksia hyvän työn toteuttamisen näkökulmasta. Liminaalisuus voi olla ahdistava kaaos, mutta toisaalta täynnä voimaa ja potentiaalia, jolloin se mahdollistaa ennalta suunniteltujen asioiden tapahtumisen. (Turner 1979, 465-66).

Työelämän yksilöllistymisen rinnalla on tapahtunut työyhteisöjen ja organisaatioiden muutos (Garsten 1999). Pysyvien organisatoristen rakenteiden oheen on syntynyt verkostomaisia työympäristöjä (Nohria ja Eccles 1992), joissa työtä tehdään muuttuvissa asiantuntijakokoonpanoissa, joustavissa työsuhteissa ja väliaikaisissa solmuissa (Engeström 2004; 2008). Organisaatioiden ja työyhteisöjen luonteella on vaikutuksia myös organisaation oppimiseen ja luovuuteen. Organisaatiomuutoksen, oppimisen ja tiedon tuottamisen tutkimuksessa on käytetty tilaan ja liikkumiseen liittyviä metaforia. Uuden tiedon luomisen on nähty olevan mahdollista yhteisessä - fyysisessä tai virtuaalisessa - vuorovaikutustilassa. Tällaisia tiloja ovat esimerkiksi " $b a$ " (Nonaka ja Konno 1998), "organisaation muistitila" (organizational memory space) (Karsten 1999) sekä innovaatioihin yhdistetty "välimaasto" (Johansson 2004). Liminaalitilan käsite sisältää näille käsitteille tyypillisiä liikkumisen, luovuuden ja uuden luomisen elementtejä.

Liminaalitila (liminal state; Turner 1977) on antropologiassa määritelty välitilaksi, kynnyksellä olemiseksi. Alkuperäinen antropologinen rituaalitutkimukseen liittyvä käsite on nykykeskusteluissa siirretty uudenlaisiin konteksteihin ja se on saanut erilaisia tulkintoja. Käsitettä on käytetty viimeaikaisessa organisaatiotutkimuksessa muun muassa organisaatioluonteen, määräaikaisten ja projekteissa työskentelevien työtekijöiden kokemusten sekä konsulttien ja asiakasorganisaation suhteiden tutkimuksessa. Yleisemmin on todettu, että liminaalisuus on nykypäivän työelämälle ominainen piirre, joka haastaa teollisuusyhteiskunnan vanhat rakenteet ja työn organisoitumisen tavat sekä mahdollistaa uusia ja luovia työn organisoitumisen ja kokemisen tapoja (Garsten 1999).

Työelämän ja organisaatioiden moniulotteisissa muutoksissa myös johtajuuden perusteita on tarkasteltava uudelleen. Hamel (2007) esittää, että nykyjohtajuus ei ole pysynyt muutosten vauhdissa, vaan toteuttaa edelleen teollistumisen kaudella kehitettyjä, järjestyksen luomisen metaforaan perustuvia johtamistapoja. Uuden sukupolven ei-hierarkkista johtajuutta on kuvattu esimerkiksi kaverijohtajuutena (Tapscott 2010; Tienari \& Piekkari 2011).Johtamiskirjallisuudessa on esitelty uudenlaisia johtamistyylejä ja -konsepteja, jotka omalta osaltaan pyrkivät vastaamaan muuttuneen työelämän tarpeisiin (Seeck 2008). Esimerkiksi innovaatioteorioihin perustuvat johtamisparadigmat olettavat, että työntekijöitä ohjaa jatkuva tarve uudistua ja halu käyttää tietämystä ja luovaa potentiaalia. Työntekijöiden sitouttamisen ja urapolun tarjoamisen sijaan johtamisen tavoitteena on organisaation jatkuva uudistuminen ja kyky sopeutua nopeasti markkinoiden muuttuviin tarpeisiin.

\section{LIMINAALITILAN OMINAISPIIRTEET: KATSAUS VICTOR TURNERIN AJATTELUUN}

Liminaalitilan käsitteen tärkein piirre on sen prosesiluonne. Liminaalisuus kuvaa tilaa, jossa ollaan välissä, ei enää - ei vielä, "the betwixt and between". Termi on 
johdettu latinan sanasta limen (kynnys). Sen juuret ovat ranskalaisen etnologin Arnold van Gennepin (1909) tutkimuksissa, joissa hän hahmotteli siirtymäriittien (rites de passage) universaaleja ominaisuuksia. Hänen mukaansa rituaaleissa oli tunnistettavissa kolmivaiheinen prosessi: ensimmäisessä vaiheessa riittiin osallistuja erotettiin jokapäiväisen elämän paikasta, suhteista ja käytännöistä. Toisessa vaiheessa oltiin marginaalitilassa; tilassa, jossa normaalit roolit, rakenteet ja normit eivät päteneet, ja jossa rituaaliin osallistujat olivat muulle yhteisölle olemattomissa, "kuolleita". Kolmannessa vaiheessa palattiin tavalliseen elämään muuttuneina ja uuden statuksen ja identiteein saaneina.

Afrikkalaisten rituaalien tutkijana uransa aloittanut antropologi Victor Turner (1920-1983) kutsui toisen vaiheen marginaalitilaa liminaalitilaksi (Turner 1977, 36; 1986, 25). Turner myös laajensi ja kehitti käsitettä eteenpäin. Hän esitti (1977, 37), että liminaalitilaa voi kuvata kynnyksen sijaan ”tunnelina”, pitkänä matkana dynaamisesta staattiseen. Myös Richard Schechner (1988/2003) liikkuu van Gennepin ja Turnerin jalanjäljissä tutkiessaan sosiaalisen draaman ulottuvuuksia eri kulttuureissa ja yhteisöissä. Turnerin ja Schechnerin kautta avautuu mahdollisuus ymmärtää liminaalisuuden sosiaalisia ilmentymiä ja rituaalisuutta jokapäiväisessä elämässä. Rituaali on joukko tekoja tai liikkeitä, jotka tehdään niiden symbolisen arvon vuoksi. Rituaali voi tukea siirtymistä (sosiaalisesta) asemasta toiseen, kuten esimerkiksi ikäkausitatuksen muutoksessa, uuteen virkaan astuttaessa tai avioiduttaessa.

Antropologina Turner sijoittuu funktionalismin ja strukturalismin tutkimusperinteiden välimaastoon. Turnerin näkemyksissä rituaalin tehtävä on tuottaa ja ylläpitää sosiaalista järjestystä ja rakennetta. Hän eli kautta, jolloin strukturalistinen antropologia sai osakseen kasvavaa kritiikkiä, ja kulttuurien ”staattisen kuvaamisen" sijaan pyrittiin ymmärtämään sosiaalisia prosesseja (Turner 1986, 21). Turnerkin käsitteellisti rituaalit myös sosiaalisina prosesseina, jotka saattoivat mahdollistaa muutoksen ja yhteisön uudelleen määrittelyn (Bell 1997, 39).

Uudelleen määrittelyn mahdollisuus liittyy rituaalien performatiivisuuteen. Turner (1986, 21-22) käyttää Milton Singerin (1972) termiä kulttuurinen performanssi. Hänen teesinsä on, että kulttuurinen performanssi ei "kuvaa" sosiaalista systeemiä, vaan suhde on molemminpuolinen ja refleksiivinen - performanssi on usein sosiaalisen elämän kritiikkiä. Rituaaleissa ja performansseissa esitetään, kyseenalaistetaan ja jopa saatetaan naurunalaiseksi vallitsevat rakenteet ja normit. Turnerin käsitys rituaaleista on evolutiivinen $(1986,11)$ ja hän esittää, että inhimillisten rituaalien kirjo kasvaa ja luonne muuttuu yhteiskunnallisen kehittymisen ja eriytymisen myötä. Myöhemmässä uravaiheessa Turner suuntasi kiinnostuksensa etenkin modernien yhteiskuntien sosiaalisen ja esteettisen yhdistäviin performatiivisiin genreihin rituaalisena toimintana. Pääideana oli, että jatkuva dynaaminen prosessi yhdistää performatiivisen käyttäytymisen (taide, urheilu, rituaali, leikki, peli) olemassa olevaan yhteisölliseen ja eettiseen rakenteeseen (Schechner 1986, 8). Viimeiseksi jääneessä teoksessaan The Anthropology of Performance Turner päätyy nojautumaan Ronald Grimesin muotoilemaan rituaalin määritelmään: rituaali on "muutoksia aikaan saava performanssi, joka tuo näkyväksi kulttuurisiin prosesseihin sisältyviä olennaisia luokituksia, kategorioita ja vastakkainasetteluita." (Turner 1986, 75).

Turner esitti (1977, 43; Schehner 1986, 9), että liminaalisuuden sijaan moderneissa yhteiskunnissa voisi käyttää käsitettä liminoidi; liminaalin kaltainen. Liminoideja ilmiöitä ovat esimerkiksi teatteri, karnevaalit tai urheilukisat; jotka eivät ole liminaalisten tapahtumien tavoin sidottuja yhteisöllisiin vuodenaikaan tai ikäryhmiin liittyviin sykleihin, vaan niitä luonnehtii yksilöllinen vapaa-ajan osallistuminen (Turner 1977, 44). Modernin yhteiskunnan rituaaleihin liittyy myös maallistuminen ja pyhän merkityksen väheneminen (ks. esim. Crosby 2009) sekä mahdollisuus tuottaa yhteisten merkitysten rakentamisen lisäksi radikaalia kritiikkiä ja utopioita (Turner 1977, 45). Organisaatiotutkimuksen käyttöön on kuitenkin vakiintunut liminoidin sijaan liminaalisuuden käsite ${ }^{3}$ vaikka tutkimuskohteet sijoittuvat moderneihin ja jälkimoderneihin yhteiskuntiin. 


\section{UUDEN LUOMINEN JA REFLEKTIIVISYYS}

Liminaalitila - niin traditionaalisessa kuin modernissa merkityksessäänkin - sisältää kokeilun ja leikin mahdollisuuden (Turner 1979, 468). Liminaalitilassa voidaan leikitellä merkityksillä ja rooleilla, ja olemassa olevat erottelut liukenevat. Asiat vaikuttavat sekavilta ja epävarmoilta, ja niillä voi olla monia samanaikaisia merkityksiä. Liminaalitilassa olevat ihmiset ovat ikään kuin väliaikaisesti "normatiivisen rakenteen ulkopuolella”. Tämä toisaalta heikentää henkilöiden asemaa - esimerkiksi puuttuvien oikeuksien kautta - mutta myös vapauttaa heidät rakenteellisista velvollisuuksista (Turner 1982). Liminaalitila on eräänlainen luova kaaos, jossa normaalielämän säännöt ja rutiinit eivät päde. Liminaalitilassa on paljon potentiaalia, "mitä tahansa" voi tapahtua (Turner 1979; 468). Tämä tila mahdollistaa yleensä uuden luomisen ja luovuuden, mikäli sitä osataan hyödyntää riittävästi. Turner liittää liminaalisuuteen virtauksen (flow) käsitteen (Csikszentmihalyi 1990). Flow on kokonaisvaltainen, luovuuden mahdollistava tunne, joka liittyy totaaliseen keskittymiseen ja mukana oloon. Liminaalitilassa on mahdollisuus yhteisöllisen, jaetun flow-tilan saavuttamiseen.

Liminaalitilan performatiivisuuteen liittyy reflektiivisyys, joka mahdollistaa jokapäiväisen elämän uudenlaisen tarkastelun (Turner 1986, 24). Arkisen työn normaalit rutiinit ja merkitykset näyttäytyvät toisenlaisina ja ovat reflektion ja jopa parodian kohteena. Traditionaalisten yhteiskuntien rituaaleissa käytetyt naamiot ja puvut eivät ole sattumanvaraista rekvisiittaa, vaan tuovat jokapäiväisen elämän normit korostetusti esille ja rikkovat "normaalin" ja "mystisen" rajoja (Turner 1977, 38). Liminaalitilassa reflektio on mahdollista kohdistaa myös itseen; itse ja oma työ näyttäytyy ”toisena”. Tähän subjektin ja objektin rajojen rikkoutumiseen liittyy myös transformaation, muuttumisen, mahdollisuus (Turner 1986, 24-25). Toiminnasta voidaan tuottaa erilaisia luovia variaatioita, jotka voivat liittyä esimerkiksi toimijoiden roolien, vaikkapa muutoksen kohteesta muutosagentiksi, vaihtoehtojen muuntelun. Liminaalitilassa mahdollistuu metakielen tuottaminen; puhutaan jokapäiväisestä kielestä ja käytännöistä refleksiivisesti (Turner 1986, 25, 32; 1977, 45).

\section{ANTIRAKENNE JA AUKTORITEETIN ROOLI}

Turner esittää (1977, 37, 48), että siirtymävaiheessa olevat ovat tietyllä tavalla vallitsevien poliittisten ja laillisten rakenteiden välissä eivätkä sovi normaaleihin luokituksiin. Liminaalitilassa olevien kesken voi syntyä horisontaalinen antirakenne, samankaltaisuuden yhteisö, jota Turner kutsuu termillä communitas. Tälle väliaikaiselle yhteisölle syntyy uudenlainen me-tunne, ja mahdolliset omat rituaalit. Tämä näkyy työn arjessa esimerkiksi seuraavalla tavalla: kun työpaikalla muodostuu uhka muutoksesta (esim. irtisanominen), se saattaa ajaa työntekijät emotionaaliseen välitilaan ja siten vahvistaa uudella tavalla yhteenkuuluvuuden tunnetta. Communitas on Turnerille suhde konkreettisten, historiallisten, erityisten yksilöiden välillä. Liminaalitilassa nämä yksilöt eivät kohtaa toisiaan tavanomaisten roolien tai statusten puitteissa, vaan voivat vapaasti luoda uudenlaisia suhteita.

Turner tekee jaottelun spontaanin, ideologisen ja normatiivisen communitaksen välille. Spontaani tai eksistentiaalinen on Turnerille äkillisesti syntyvä ja väliaikainen kokemus yksilöiden välisestä jakamisen tilasta. Ideologinen communitas on tapa jäsentää ja kuvata spontaanin communitaksen kokemusta - se voi olla esimerkiksi utooppinen yhteiskuntamalli. Normatiivinen communitas taas merkitsee pyrkimystä tuottaa pysyvä sosiaalinen järjestys, joka perustuu koettuun spontaaniin communitakseen (Turner 1969, 131-132; 1982, 47-59).

Traditionaalisissa siirtymäriitteihin liittyvissä liminaalitiloissa tunnusomaista on yhteisön vanhojen jäsenten absoluuttinen auktoriteetti. Koko yhteisön järjestystä voi kuvata selkeillä ja ymmärrettävillä positioilla eli henkilöiden omilla paikoilla yhteisönsä jäseninä. Yksilöiden ja yhteisöjen uskomuksia voidaan tehdä näkyviksi ja muokata rituaalien avulla. Auktoriteeteilla ja erityisesti yhteisön vanhoilla jäsenillä on uskomuksia, jotka levittyvät koko yhteisön näkymättömiksi säännöiksi. Liminaalitila on juuri paikaltaan siirtymisiä. Auktoriteetin rooli on strukturoida prosessia - vaikka kyseessä on kaaos, se ei ole mikä tahansa kaaos. Tarkoituksena on päästä kohti jotain uutta, joidenkin turvallisena koettujen toimintapojen puitteissa. 


\section{LIMINAALITILA-KÄSITE TYÖYHTEISÖJEN TUTKIMUKSESSA}

Liminaalisuus on viime vuosina vakiintunut organisaatiotutkimuksen käsitteistöön. Termi (liminality) löytyy esimerkiksi teoksen International Encyclopedia of Organizational Studies hakusanoista. Hakusanamääritelmässä liminaalisuus on uusien ja vanhojen sosiaalisten rakenteiden välisessä siirtymätilassa olemista (Tempest 2007, 821). Liminaalitilan kolmivaiheinen prosessikuvaus (irrottautuminen, liminaalitilassa oleminen, paluu) on potentiaalinen kuvaus työyhteisöjen ja organisaation muutoksesta. Esittelemme liminaalisuus -käsitteen käyttöä viimeaikaisessa työyhteisöjen tutkimuksessa. Olemme jaotelleet tutkimukset kolmeen erityyppiseen liminaalitilan käyttökontekstiin: intentionaalinen organisaatiomuutos, organisaation ominaispiirteet sekä joustavien työsuhteiden luonnehtima uusi työelämä.

\section{INTENTIONAALINEN LIMINAALISUUS ORGANISAATION MUUTOKSESSA}

Liminaalitilan käsite soveltuu hyvin organisaatiotutkimuksen lähestymistapoihin, joissa organisaatio ja työyhteisö käsitteellistetään organisaatiokulttuurina (Schein 1992). Näille lähestymistavoille on luonteenomaista antropologiasta lähtöisin olevien käsitteiden hyödyntäminen modernien työyhteisöjen tutkimuksessa. Organisaatiomuutos voidaan antropologian viitekehyksessä ymmärtää kulttuuristen merkitysten, rituaalien, normien ja arvojen muutoksena (Easteryby-Smith 1997; Morgan 2006, $115-$ 148). Organisaatiotutkimuksessa on käytetty erottelua episodisen ja jatkuvan muutoskäsityksen välillä (Weick \& Quinn 1999). Episodisella viitataan tietoisen interventioon, usein ulkopuolisen muutosagentin fasilitoimaan organisatoriseen muutokseen, jolla on alku ja loppu, ja jonka jälkeen organisaatio palaa normaaliin tasapainotilaan. Jos muutos nähdään episodiseksi, on näkökulma usein sen tahon, joka haluaa ottaa käyttöön esimerkiksi uuden (tieto)järjestelmän tai työtavan (Lyytinen \& Newman 2008).

Jatkuva muutoskäsitys puolestaan olettaa organisatorisen muutoksen tapahtuvan vähitellen, jatkuvasti työn arjessa ilman ulkopuolista interventiota. Tällaisen muutoksen keskellä on vaikea nähdä sen tosiasiallista luonnetta. Organisaation kulttuurisen muutoksen jäsentäjänä on yleisesti käytetty sosiaalipsykologi Kurt Lewinin kenttäteoriaan pohjautuvaa (1958) jäävuorimalliksi kutsuttua vaiheistusta: sulattaminen, muutos ja uudelleen jäädyttäminen (unfreezing-freezing-refreezing). Episodisessa muutoskäsityksessä lähdetään liikkeelle sulatusvaiheesta, jolloin pehmennetään muutosvastarintaa, opitaan pois vanhasta ja puretaan olemassa olevia rakenteita ennen muutoksen tekemistä. Muutosta seuraa uusien rakenteiden, merkitysten ja käytänteiden vakinnuttaminen. Jatkuvaan muutoskäsitykseen perustuvat intentionaaliset pyrkimykset voidaan aloittaa jäädytys-vaiheesta, jossa organisaatiossa käynnissä olevia muutosprosesseja analysoidaan ja tuodaan näkyviksi (Weick \& Quinn 1999). Molempien muutoskäsitysten suhteen on pohdittu muutosagentin, joko ulkopuolisen tai organisaation sisältä nousevan muutoksen fasilitoijan tai ohjaajan roolia. Tällainen agentti nykytyöelämässä on usein organisaation ulkopuolinen konsultti, joka asettuu erilaisiin rooleihin työyhteisöön nähden.

Howard-Grenville ym. (2011) käyttävät liminaalitilan käsitettä organisaatiokulttuurin jatkuvan muutoksen analyysissa. He ehdottavat, että muutos ei tarvitse isoja, ulkoisten muutosagenttien tekemiä interventioita, vaan voi tapahtua organisaation tavallisessa toiminnassa, sisäisten toimijoiden toteuttamana. Organisaatiokulttuurin muutos ei heidän mukaansa (mt. 525) tarvitse Lewinin (1947) "kulttuuristen saarekkeiden" kaltaisia tiloja, joissa työntekijät siirretään pois jokapäiväisestä ympäristöstä sulatusvaiheen ja poisoppimisen mahdollistamiseksi. Howard-Grenville ym. esittävät, että organisaatiokulttuurin muutoksen edesauttamiseksi jokapäiväiset tapahtumat, kuten kokoukset, voidaan rakentaa arkisesta työstä erillään oleviksi liminaalitiloiksi, joissa organisaation rakenteiden merkitys etääntyy. Muutoksen kannalta on olennaista, että näissä liminaalitiloissa organisatoriset merkitykset ja symbolit nostetaan esille ja osallistujat rohkaistuvat reflektoimaan omaa ajatteluaan, kuvittelemaan ja kokeilemaan uutta. Onnistuessaan liminaalisuuden tarkoituksellinen luominen ja siihen liittyvä tutun ja tuntemattoman yhteentuominen voivat saada ai- 
kaan uudenlaisia merkityksiä. Esimerkkitapauksessa organisaatiossa valmistettujen tuotteiden ekologisuuden merkitys työntekijöille muuttui negatiivissävytteisestä "riskistä" positiiviseen "innovaatioon" (Howard-Grenville ym. 2011, 534). Liminaalisuuden tarkoituksellinen luominen onnistuu, jos organisaatiokulttuurissa on tilaa uusille merkityksille ja tilaisuuksissa tapahtuva irrottelu koetaan legitiimiksi ja turvalliseksi.

Muuttuvassa työelämässä ja eri puolilla maailmaa verkostomaisesti sijaitsevissa monikulttuurisissa organisaatioissa pysyvän organisaatiokulttuurin käsite ei välttämättä päde. Organisaation sisäiset merkitykset, normit ja arvot ovat jatkuvan tulkinnan ja neuvottelun kohteina, ja niitä sopeutetaan jokapäiväisesti laajempien kulttuuristen kontekstien arvoihin ja käytänteisiin (vrt. Hofstede 2003). Cunha kumppaneineen (2010) on tutkinut tätä ilmiötä limiaalisuuskäsitteen kautta erityisesti eettisessä johtajuudessa. Monimerkityksellisissä työyhteisöissä johtaja löytää itsensä usein eettisestä liminaalitilasta; välitilasta, jossa ei ole aivan selvää, mitkä asiat ovat oikeita, mitkä vääriä, ja jossa päätöksiä ei voida tehdä pelkästään olemassa olevien sääntöjen perusteella. Kirjoittajat (Cunha ym. 2010, 194) esittävät, että liminaalisuus on välttämätön ilmiö kompleksisissa, monenlaisissa ympäristöissä toimivissa organisaatioissa.

Orgnisaation intentionaalisten ja episodisten muutosten edesauttajina, muutosagentteina käytetään usein konsultteja. Czarniawskan ja Mazzan (2003) mukaan konsultointi mahdollistaa liminaalitilan niin konsulteille kuin organisaatioillekin. He kuvaavat konsultointitoimintaa "konsultointiriitteinä" ja paikkaa, jossa nämä riitit tapahtuvat, "liminaalisena organisaationa”. Konsultti on organisaation kanssa työskennellessään toisaalta jonkun pysyvän organisaation jäsen, toisaalta väliaikainen "vierasjäsen" asiakasyrityksessä. Konsultoinnin rituaaleiksi voidaan ymmärtää vaikkapa aloituskokous, muutosvaihe ja raportin esittäminen (Czarniawska ja Mazza 2003), jotka voidaan nähdä analogisina perinteiselle kolmivaiheiselle rituaalikuvukselle. Aloituskokous on alkutilanne, jonka jälkeen alkaa liminaalinen muutosvaihe. Raportin esittäminen ja konsulttien poistuminen edustaa paluuta muuttuneeseen normaaliin.
Konsulttien näkökulmasta katsottuna muutosvaiheen liminaalitila ja liminaali organisaatio ovat konsulttien samanaikainen näkemys organisaation nykytilanteesta ja tulevaisuudesta. Muutosvaiheeseen sisältyy vuorovaikutusta ja konsulttien ja organisaation työntekijöiden neuvotteluja tulkinnoista. Konsultti on aktiivinen liminaalitilan ja siirtymäriitin organisoimisessa ja mahdollistaa uusien organisatoristen representaatioiden syntymistä. Tämä siirtymätila ja uuden luominen voivat näyttäytyä "maagisina”, koska prosessin yksityiskohtia ei paljasteta työntekijöille. Heidän näkökulmastaan konsultoinnin tulokset syntyvät jonkinlaisen mystisen toiminnan tuloksena. Konsulttien raportin esittely on riitin irtautumisvaihe, jonka jälkeen organisaatio palaa liminaalitilasta jokapäiväiseksi työorganisaatioksi. (Czarniawska ja Mazza 2003). Tässä näkemyksessä konsultit tietyllä tavalla rinnastuvat perinteisten riittien organisoijiin, yhteisön auktoriteetteihin ja maagisissa positioissa oleviin, joita usein luonnehtii - konsulttien tavoin -, vain osittainen tai väliaikainen kuuluminen tiettyyn yhteisöön.

Sturdy, Schwartz ja Spicer (2006) ovat tutkineet konsultointia ottaen erityiseen tarkasteluun konsultointiprosessiin liittyvät liikeillalliset. Heidän analyysissaan liminaalisuus tarkoittaa rajojen radikaalia hämärtymistä. Liminaalisuus on formaalien instituutioiden välillä oleva tila, jossa olemassa olevat säännöt ja rutiinit eivät päde. Illalliset ovat tietynlaisia liminaalitiloja, joissa työelämän ja vapaa-ajan toimintatavat sekoittuvat. Aterioiden aikana johtajien, konsulttien ja työntekijöiden välillä tapahtuvat keskustelut laajenevat yksityiselämän aiheisiin ja mahdollistavat organisaation rakenteista irtaantumisen. Ruokailupaikat ovat fyysisiä työpaikasta irtaantumisen tiloja, jotka toisaalta tarjoavat jotakin tuttua ja turvallista. Liikeillalliset tarjoavat liminaalitilan, jota sekä konsultit että asiakkaat voivat käytää taktisesti hyväkseen. Sturdyn ja kumppaneiden mukaan esimerkkitapauksessa illallisia käytettiin keskinäisen luotettavuuden testaamiseen, organisaation sisäisiin valtasuhteisiin tutustumiseen sekä ideoiden testaamiseen ja myymiseen. Sen lisäksi työyhteisön vakiintuneista rakenteista irralliset tilanteet mahdollistivat kyynisyyden ja turhautumisen käsittelyn. Vaikka illalliset tarjosi- 
vat organisaation rutiineista ja normeista irrallaan olevan liminaalitilan, niissä noudatettiin kuitenkin turvallisuutta luovia muiden elämänalojen konventioita ja rutiineja.

\section{LIMINAALISUUS ORGANISAATION OMINAISUUTENA}

Liminaalisuus voi kuvata myös organisaation tilaa erilaisten perinteisten ja totuttujen organisaatiorakenteiden välillä. Organisaatiotutkimuksessa organisatorinen ambivalenssi (Weick 1979) kuvaa ilmiötä, jossa erilaiset organisatoriset logiikat ja rakenteet sekoittuvat ja muodostavat hybridejä. Organisaatiologiikat voidaan yhdistää erilaisiin institutionaalisiin järjestyksiin, esimerkiksi valtion byrokratiaan, yksityiseen sektoriin tai arvoperustaiseen kansalaisyhteiskuntaan), jolloin organisaation logiikka seuraa institutionaaliselle järjestykselle ominaisia piirteitä. (Thorton ym. 2012; 2008). Viimeaikaiset työelämän muutokset ovat lisänneet logiikoiden sekoittumista sektorilta toiselle. Lisääntyvän managerismin myötä esimerkiksi terveydenhuollossa julkisen sektorin palvelujen universaalisuuden logiikka, terveydenhuollon ammattilogiikka ja voiton tavoittelun markkinalogiikka sekoittuvat organisaatioiden käytännön toiminnassa (Scott ym. 2000). Osuuskunnissa ja kansalaisjärjestöissä kolmannen sektorin ja markkinoiden logiikat yhdistyvät, kun taas taidetyössä voidaan puhua taiteen laadun ja markkinalogiikan jännitteistä.

Organisatorinen monimuotoistuminen näkyy myös käytännön organisaatiorakenteissa. Organisaatioissa saattaa olla esimerkiksi päällekkäin hierarkkista toimintatapaa edellyttävä byrokraattinen logiikka ja luottamukseen perustuva verkostomainen organisoitumislogiikka (Powell 1990), mikä näkyy käytännössä vaikkapa päällekkäisissä, erilaisia valtakäsityksiä (Seeck 2008) totetuttavissa johtamismuodoissa. Jatkuvat organisaatiomuutokset voivat johtaa siihen, että työyhteisö on jatkuvassa välitilassa vaikkapa linja- ja tiimiorganisaation välillä. Yksilöllistyvä työ on myös haastanut "työyhteisön" käsitettä. Työyhteisö ei ole välttämättä tietty organisaatio, vaan fyysinen työtilayhteisö (co-working community), jossa yksittäiset itsensä työllistäjät työskentelevät ja jakavat osittain tiettyjä yhteisöllisiä elementtejä. Työtilayhteisöjä on listattu kansainvälisesti esimerkiksi verkkosivuilla www.deskwanted.com ja www.deskmag.com. Näitä paikkoja tarkasteltaessa kysymys työn merkityksellisyydestä, identiteetistä tai yhteisöllisyydestä nousee keskeiseksi. Työtilayhteisöjen dynamiikka ja työntekijöiden syyt hakeutua yhteisöihin on uusi tutkimuskohde työlämän tutkimuksessa (ks. Spinuzzi 2012).

Liminaalitilan käsite on tarjonnut käsitteellisiä välineitä jäsentää organisatorisia muutos-, hybridi- ja välitiloja. Esimerkiki Lindsay (2010, 165) on käyttänyt organisatorisen liminaalisuuden (organizational liminality) käsitettä analysoidessaan monimerkityksellistä organisaatiota, joka tietoisesti on pyrkinyt rikkomaan luutuneita organisaatiokäsityksiä ja perinteisiä rakenteita ja institutionaalisia kategorioita niin organisaation sisällä kuin ulkoisen identiteetinkin suhteen. Rikkomalla olemassa olevia ja totuttuja rakenteita organisaatio aiheuttaa toisaalta epävarmuutta, toisaalta mahdollistaa uusien ja luovien ratkaisujen syntymisen. Ulkoiselta identiteetiltään liminaalit organisaatiot saattavat olla spontaaneja, epäennustettavia ja jopa mystisiä (Lindsay 2010, 89, 167). Liminaalin organisaation ulkoisia merkkejä voivat olla esimerkiksi käyntikortit, joista ei ilmene työntekijän työnimekettä tai hierarkkista asemaa.

Organisatorinen liminaalisuus ja organisaation hybridimuodot voivat kertoa myös ei-suunnitellusta toimintalogiikoiden sekoittumisesta. Tämä voi näyttäytyä ahdistavana kaaoksena. Liminaalitilan käsite voi tarjota välineitä kaaoksen jäsentämiseen ja esimerkiksi selventää, onko organisaation nykytilanteessa päällekkäin linja- ja tiimiorganisaation piirteitä. Se tarjoaa myös mahdollisuuden kysyä, mihin tilan mahdollistamaan suuntaan voidaan siirtyä, ja voidaanko palata niin sanottuun muuttuneeseen normaalitilaan.

\section{LIMINAALISUUS JOUSTAVIEN TYÖSUHTEIDEN KONTEKSTISSA}

Organisaatiotutkimuksessa on myös esitetty, että liminaalisuus ei tämän hetkisessä työelämässä ole enää hallitun kolmivaiheisen prosessin keskimmäinen vaihe, vaan enemmän tai vähemmän pysyvä tila (Czarniawska ja Mazza 2003). Liminaalisuudesta on näiden käsitysten mukaan tullut osa työelä- 
mää, jota luonnehtivat pätkätöistyminen (Garsten 1999, 608), monimerkityksellisyys ja kompleksisuus (Cunha ym. 2010, 194). Liminaalitila ei välttämättä ole toivottu ja intentionaalisesti rakennettu tila, vaan se näyttäytyy tilana, johon työntekijät ajautuvat ja joka pakottaa työntekijöitä uudenlaisten identiteettien luomiseen. Toisaalta modernin työelämän rutinoitunut, monille ammattilaisille itsestäänselvyytenä oleva liminaalitila, mahdollistaa jatkuvat pienet innovaatiot työn arkipäivässä.

Työelämän joustavuusvaatimukset ovat lisänneet työntekijöiden liikkuvuutta organisaatioista ja projekteista toiseen. Joustavat työntekijät työskentelevät määräaikaisissa työsuhteissa, vaihtuvissa työtiimeissä ja verkostoissa eivätkä vakituisten työtekijöiden tapaan identifioidu tiettyyn organisaatioon ja työyhteisöön. Liminaalisuuden käsitettä on käytetty jäsentämään sekä joustavien työntekijöiden toimijuutta subjektin näkökulmasta että joustavan työvoiman käytön vaikutuksia organisaation rakenteisiin ja toimintatapoihin. (Garsten 1999; Tempest \& Starkey 2004). Garsten $(1999,603)$ muistuttaa, että ilmiö on ristiriitainen, ja joustava pätkätyö voidaan nähdä sekä haitallisena että hyödyllisenä niin organisaatioiden kuin työtekijöidenkin kannalta. Liminaaliseksi tilanne muodostuu siksi, että vaikka työntekijöiltä puuttuu vakituisen työsuhteen tarjoama rakenteellisen side organisaatioon, he kuitenkin ovat osittain mukana esimerkiksi erilaisissa organisaation lojaalisuusverkostoissa.

Määräaikaisen työntekijän liminaalitila voi olla esimerkiksi tie vakituiseen työsuhteeseen, umpikuja tai siirtymävaihe kahden uran välillä. Tämänkaltainen positioiden "välissä oleminen" synnyttää refleksiivisyyttä ja lisää työntekijän itsekontrollia. Liminaalitila voi kuitenkin olla vakiintuneita rakenteita otollisempi tila työntekijän innovoinnille. Tilanteeseen liittyy siis sekä marginaalisuuden että potentian kokemuksia, sosiaalisen kuulumattomuuden tunnetta, mutta toisaalta myös oikeutus pysytellä työpaikan sosiaalisten konfliktien ulkopuolella (Garsten 1999, 604-606). Työyhteisön kehittymisen kannalta määräaikaiset työsuhteet tarkoittavat usein lisääntyvää episodimaisuutta ja haurautta. Liminaalitilassa olevat työntekijät ovat haaste rakenteille - työntekijät ovat kulttuurin ja yhteiskunnan kannalta "määrittelemättömässä" tilanteessa. Työntekijät ovat melkein osa organisaation rakennetta, mutta ei aivan. Jatkuvasti tulevat ja menevät työntekijät voivat ravisuttaa organisaatioiden järjestystä ja institutionaalisia rajoja (mt. 615). Määräaikaisten työtekijöiden ohella liminaalisuus on liitetty myös työntekijöiden identiteetin rakentumiseen ennen kaikkea organisaation muutostilanteissa (Beech 2011). Työntekijöiden voidaan nähdä rakentavan ulkoista ja sisäistä identiteettiään dialogin kautta suhteessa organisaatioon ja muihin työntekijöiden liminaalisten käytäntöjen, kuten kokeilujen, reflektion ja tunnistamisen kautta (mt. 289-290).

Sue Tempest ja Ken Starkey (2004) keskustelevat Garstenin esittämästä liminaalisuuden tulkinnasta organisatorisen oppimisen näkökulmasta. He ovat Garstenin kannalla siinä, että vaihtuvat määräaikaistyöntekijät voivat mahdollistaa uudenlaista organisatorista oppimista, mutta esittävät, että liminaalisuudella on myös rajansa. Kun oppiminen tapahtuu yhä enemmän organisaatioiden välisissä verkostoissa ja tiimeissä, se heikentää perinteissä mielessä ymmärrettyä organisaation oppimista sekä rapauttaa organisaatioiden sosiaalista pääomaa (Tempest \& Starkey 2004, 510). Individualisoitu työ tuottaa individualisoitua oppimista, jonka tulokset eivät välttämättä tule organisaatioiden hyödyksi. Työn yksilöllistymisen on nähty jopa tekevän yhdessä oppimisesta ja toisista riippuvuudesta jollakin tapaa "laitonta" (Sennett 1998). Jatkuva työyhteisöjen ja työntekijöiden liminaalitila on jännitteinen tila, jolla on sekä innovaatioita mahdollistavia että työelämää huonontavia vaikutuksia.

\section{JOHTOPÄÄTÖKSET}

Liminaalitilan käsitettä on katsauksemme perusteella käytetty organisaatiotutkimuksessa monenlaisissa merkityksissä (ks. yhteenveto Taulukko 1). Erottelimme aikaisempien tutkimusten pohjalta kolme erilaista liminaalitilan käyttökontekstia: (1) intentionaalinen organisaation muutos, (2) organisaation rakenteen ja identiteetin ominaisuus sekä (3) joustavien työsuhteiden luonnehtima työelämä. Jokaisessa kolmessa käyttökontekstissa käsitettä on sovellettu useilla tavoilla ja Turnerin alku- 
Taulukko 1. Yhteenveto liminaalitilan käsitteestä työympäristöjen tutkimuksessa

\begin{tabular}{|l|l|l|}
\hline \multicolumn{1}{|c|}{ Käsitteen käyttökonteksti } & \multicolumn{1}{|c|}{ Käsitteen sovellus } & \multicolumn{1}{c|}{ Esimerkkitutkimus } \\
\hline $\begin{array}{l}\text { Intentionaalinen } \\
\text { organisaation muutos }\end{array}$ & $\begin{array}{l}\text { Organisaatiokulttuurin muutosrituaalin vaihe, joka on usein } \\
\text { ulkoisen muutosagentin organisoima. }\end{array}$ & $\begin{array}{l}\text { Czarniawska \& Mazza 2003 } \\
\text { Sturdy ym. 2006 }\end{array}$ \\
\hline $\begin{array}{l}\text { Organisaation rakenteen ja } \\
\text { identiteetin ominaisuus }\end{array}$ & $\begin{array}{l}\text { Vakiintuneiden organisaatiorakenteiden ja logiikoiden } \\
\text { sekoittumisen synnyttämä tila. }\end{array}$ & Lindsay 2010 \\
\hline $\begin{array}{l}\text { Joustavien työsuhteiden } \\
\text { luonnehtima työelämä }\end{array}$ & $\begin{array}{l}\text { Liminaalitila on toisaalta modernin työelämän normaalitila, } \\
\text { toisaalta pätkätöitä tekevien työntekijöiden identiteetti. }\end{array}$ & $\begin{array}{l}\text { Garsten } 1999 \\
\text { Tempest \& Starkey } 2004\end{array}$ \\
\hline
\end{tabular}

peräisestä käsitteistöstä on noussut tärkeäksi erilaisia ulottuvuuksia. Johtopäätöksenä voimme todeta, että liminaalitilan käsite mahdollistaa erilaisia sovelluksia eikä yhtä ja kaiken kattavaa käyttötapaa voida märitellä. Käsitteen vahvuus on sen elemettien avaamat uudet mahdollisuudet ja näkökulmat yksittäisten työyhteisöjen ja yleisen työelämän tutkimuksessa. Liminaalitila ei käsitteenä ole normatiivinen kuvaus "oikeasta" muutosprosessista, vaan käsitteen elementit antavat tilaa niin negatiivisille kuin positiivisillekin tulkinnoille. Työelämän liminaalitilalla saattaa olla yksilön ja yhteisöjen kannalta kielteisiä seurauksia, mutta se voi tarjota myös myönteisen väylän vanhan purkamisen kautta kohti uudenlaisia merkityksiä. Tällöin liminaalitilan ymmärtäminen voi auttaa kestämään siihen kuuluvaa kaaosta ja haastamista, joka johtaa uudenlaiseen työn arkipäivään.

Intentionaalisen organisaation muntoksen tutkimuksessa liminaalitilalla viitataan kolmivaiheisesti etenevän organisaatiokulttuurin muutoksen keskimmäiseen vaiheeseen, jossa enemmän tai vähemmän suunnitellusti organisoidaan performatiivisuuden ja leikittelyn mahdollistava liminaalitila. Liminaalitilalla kuvataan organisaation vanhoja rakenteita ja toimintatapoja reflektoivaa muutostilaa, jonka jälkeen palataan muuttuneeseen, mutta asteittain rutinoituvaan normaalitilaan. Liminaalitilan luomiseen liittyy usein ulkopuolinen muutosagentti, konsultti, joka organisoi liminaalitilaa ja on samalla myös itse liminaalisessa suhteessa organisaatioon. Turnerin alkuperäisestä käsitteistöstä relevanteiksi nousevat kaaoksen ja järjestyksen suhde, reflektiivinen performatiivisuus ja auktoriteetin rooli liminaalitilan jäsentäjinä. Konsultin rooli voidaan rinnastaa perinteisten yhteisöjen vanhimpien jäsenten auktoriteettirooliin rituaalien järjestäjinä ja mahdollistajina.
Organisaatirakenteiden ja organisaation identiteetin kuvauksessa liminaatilan käsite on viitannut eräänlaiseen välitilaan vakiintuneiden organisaatiotyyppien, olemassa olevien organisaatiologiikkojen ja tunnettujen organisaatiorakenteiden ja -mallien välillä. Näissä merkityksissä liminaalitila voi olla tietoinen, organisaation valitsema uutta luova strategia, toisaalta erilaisten muutospaineiden luoma epämääräinen tila. Turnerin käsitteistöstä relevanteiksi nousevat olemassa olevien rakenteiden rikkominen ja jopa karnevalisointi sekä uudenlaisten, ei-vielä muodostuneiden rakenteiden performointi.

Joustavien työsuhteiden ja undenlaisen työelämän käsitteellistämisen yhteydessä liminaalitilan käsiteellä on kuvattu niin työelämän normaalistuvaa jatkuvaa muutostilaa kuin pätkätyöstä toiseen siirtyvien työntekijöiden identiteettiäkin. Käsite on liitetty yhteisöön kuulumisen ja kuulumattomuuden problematiikkaan sekä sen mukanaan tuomiin negatiivisiin ja mahdollistaviin vaikutuksiin. Tällaisen liminaalitilan on katsottu johtavan oppimisen individualisoitumiseen ja perinteisesti ymmärretyn organisatorisen oppimisen rapautumiseen.

Kaiken kaikkiaan käsite avaa mahdollisuuksia pureutua erilaisiin työelämän muutostilanteisiin, uuden luomisen ja pysyvän vanhan rakenteen väliseen dynamiikkaan sekä muutosten prosessiluonteeseen. Liminaalitila nykyisessä työkulttuurissa voi viitata työelämän laajaan muutokseen, jota luonnehtii vanhojen, pysyviin organisaatioihin ja jatkuviin työsuhteisiin perustuvien rakenteiden murtuminen sekä yksittäisen työyhteisöjen muutosten dynamiikkaan. Liminaalitila voi toisaalta olla ei-toivottu työntekijöiden ajautumisen suunta, toisaalta toivottu ja positiiviseksi koettu innovatiivinen tila. Siinä ollaan "kynnyksellä", josta avautuu monenlaisia sosiaalisen reflektion mahdollisuuk- 
sia. Turnerin käsitteiden avulla huomio kohdistuu staattisuuden ja muutoksen väliseen dynamiikkaan, performatiivisuuden mahdollistamaan reflektiivisyyteen sekä rituaaleihin, jotka mahdollistavat muutoksia ja luovat turvallisuutta. Rituaalien rooli voi olla myös vanhan ylläpitäminen ja muutoksen radikaalisuuden rajoittaminen; esimerkiksi konsulttien järjestämä liminaalitila ja sen mahdollistava kaaos on rajallinen. Liminaalitila ei ole hallitsematon kaaos, vaan turvallisuutta siihen luovat tunnetut rituaalit sekä auktoriteetin luomat puitteet. Uuden luominen ja innovoiminen on jatkuvaa vuorovaikutusta kaaoksen ja rakenteen, vapauden ja auktoriteetin, realismin ja utopian välillä.

Liminaalitilan käsitteen avulla voidaan kiinnittää huomiota työyhteisön sosiaalisiin asemiin ja kultuuriseen järjestykseen, joka voidaan tehdä näkyväksi perfomatiivisten rituaalien avulla. Performatiivisuuden, rituaalien ja jopa maagisuuden ulottuvuudet ohjaavat työelämän muutosprosesseissa huomiota niiden toiminnallisiin, tunteellisiin ja kokemuksellisiin elementteihin rationaalisesti suunnitellun ja sanallisten argumenttien kautta ohjatun muutoksen sijasta. Reflektiivisyys, leikittely, ironia ja uusien ideoiden kokeilu edellyttävät usein juuri liiallisesta rationaalisuudesta irti päästämistä.

Liminaalitilassa tapahtuva leikittely mahdollistaa myös sosiaalisiin valta-asemiin liittyvää innovatiivista toimintaa. Yksi vahvimmista työkulttuurissa vallitsevista sosiaalisista asemista on johtajan ja alaisten välinen suhde. Siirtymätilassa tätä suhdetta voidaan parodioida ja luoda enemmän tai vähemmän väliaikaisia antirakenteita, joissa organisaation sosiaalista järjestystä neuvotellaan uudelleen. Turnerilaisittain voi todeta, että paikallaan olevissa rakenteissa etsiydytään liminaaliseen leikkiin esimerkiksi pikkujouluissa tai työpaikan muissa rituaalisissa leikeissä, karnevaaleissa, joissa sosiaaliset statukset purkautuvat hetkeksi auki tai saattavat jopa vaihtaa paikkaa. Luutuneiden johtamistapojen karnevalisointi voi johtaa uudenlaisten mallien syntymiseen ja kokeiluun.

Liminaalitilan käsite avaa mahdollisuuksia analysoida työyhteisöjä, jotka tietoisesti lähtevät purkamaan vanhoja rakenteita ja jäsentämään johtajuutta uudelleen. Omassa tutkimushankkeessamme työyhteisöt pyrkivät tuottamaan uudenlaista, joustavaa johtajuutta. Se voi tarkoittaa johtaja-aseman purkamista ja vetovastuun kierrättämistä ja "johtajuuden ansaitsemista" uuden sukupolven osuuskuntayhteisöissä, parijohtajuuden valitsemista taiteellisissa työyhteisöissä, voimaistavan johtajuuden mallin etsimistä ammattilaistumissa kansalaisjärjestöissä tai joustavaa ja ketterää johtajuutta ohjelmistokehityksen projektityöskentelyssä (ks. Ansio \& Hirkman, tulossa). Työelämän muutoksiin vastaamaan pyrkivien uudenlaisten johtajuuden tapojen hahmottelussa voidaan hyödyntää liminaalitilan käsitteen eri elementtejä. Tällöin haasteeksi ja tärkeäksi tutkimuskohteeksi nousee se, millaisessa liminaalitilassa, uuden ja vanhan, kaaoksen ja järjestyksen välissä, itse johtajuuden käsite ja käytäntö ovat.

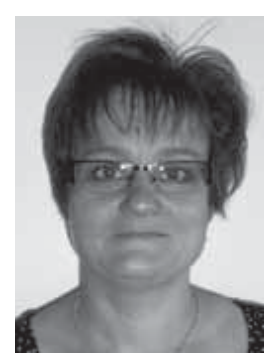

Tiina Kontinen

FT, yliopistonlehtori

Yhteiskuntatieteiden ja

filosofian laitos

Jyväskylän yliopisto

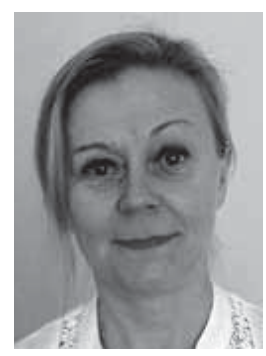

Pia Houni

TeT, dosentti, erikoistutkija Työterveyslaitos, Helsinki

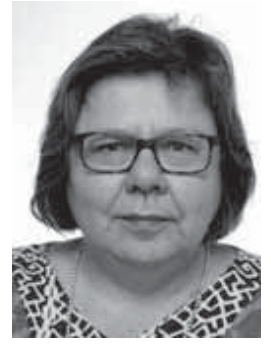

Helena Karsten

KTT, dosentti

Informaatioteknologioiden laitos Ábo Akademi

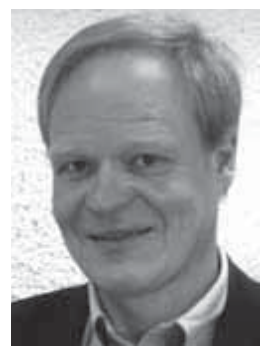

Heikki Toivanen

TkT, tiimivalmentaja

ja strategi

Tiimiakatemia

Jyväskylän ammattikorkeakoulu 
Alasoini, T. Järvensivu, A. \& Mäkitalo, J. (2012). Suomen työelämä vuonna 2030. Miten ja miksi se on toisennäköinen kuin tällä hetkellä? TEM raportteja $14 / 2012$.

Ansio, H. \& Hirkman, P. (toim.) (tulossa 2013) Työ ja johtajuus liminaalitilassa. Hankkeen loppuraportti. Tekesin raporttisarja 6/2013. Helsinki: Tekes.

Beech, N. (2011). Liminality and the practices of identity reconstruction. Human Relations 64(2), 285-302.

Bell, C. (1997). Ritual: Perspectives and Dimensions. Oxford, UK: Oxford University Press.

Butler, J. (2006). Hankala sukupuoli. Feminismi ja identiteetin kumous. Suom. Pulkkinen, Tuija \& Rossi, Leena-Maija. Helsinki: Gaudeamus.

Castells, M. (1996, $2^{\text {nd }}$ ed. 2000). The Rise of the Network Society, the Information Age: Economy, Society and Culture Vol. I. Oxford, UK: Blackwell.

Castells, M. (1997, $2^{\text {nd }}$ ed. 2004). The Power of Identity, the Information Age: Economy, Society and Culture Vol. II. Oxford, UK: Blackwell.

Castells, M. (1998, $2^{\text {nd }}$ ed. 2000). End of Millennium, the Information Age: Economy, Society and Culture Vol. III. Oxford, UK: Blackwell.

Csikszentmihalyi, M. (1990). Flow: The Psychology of Optimal Experience. New York: Harper and Row.

Ciborra C. (1996). The platform organization: Recombining strategies, structures, and surprises. Organization Science, 7(2), 103-118.

Collins, J. (2001). Good to Great. New York: Harper Collins.

Cook-Sather, A. (2006). Newly Betwixt-and-between: Revising Liminality in the Context of a Teacher Preparation Program. Anthropology and Education Quarterly 37(2), 110-127.

Crosby, J. (2009). Liminality and the Sacred: Discipline Building and Speaking with the Other. Liminalities: A Journal of Performance Studies, 5(1), 1-19.

Cunha, M.P., Guimarães-Costa, N. \& Steward R.M. (2010). Leading and Following (Un)ethically in Limen. Journal of Business Ethics (97), 189-206.

Cunha, M.P. \& Cabral-Cardoso, C. (2007). Shades of Gray: A liminal interpretation of organizational legality/illegality. International Public Management Journal 9(3), 209-226.

Cunningham,I. (1994/1999). The Wisdom of Strategic Learning. Hampshire, UK: Gower.

Czarniawska. B. \& Massa, C. (2003). Consulting as a liminal space. Human Relations 56(3), 267-290.

Easterby-Smith, M. (1997) Disciplines of Organizational Learning: Contributions and Critiques. Human Relations 50 (9), 1085-1113.

Engeström, Y. (2004). Ekspansiivinen oppiminen ja yhteiskehittely työssä. Tampere: Vastapaino.

Engeström, Y. (2008). From Teams to Knots: ActivityTheoretical Studies of Collaboration and Learning at Work. Cambridge, UK: Cambridge University Press.

Garsten, C. (1999). Betwixt and between: Temporary employees as liminal subjects in flexible organizations. Organization Studies 20(4), 601-617.

Hamel, G. (2007). Johtamisen tulevaisuus. Helsinki: Talentum Media.

Hautamäki, A., (toim.). (1996). Suomi teollisen ja tietoyhteiskunnan murroksessa: Tietoyhteiskunnan sosiaaliset ja yhteiskunnalliset vaikutukset. Helsinki: SITRA.

Von Hippel, E. (1988). Sources of Innovation. Oxford, UK: Oxford University Press.

Hoikkala, T. \& Salasuo, M. (2006). Prekaariruoska? Portfoliosukupolvi, perustulo ja kansalaistoiminta. Helsinki: Nuorisotutkimusverkosto, Nuorisotutkimusseuran verkkojulkaisusarja.

Houni, P., Ansio, H. \& Järvinen, M. (tulossa 2013). Parijohtajuus esittävän taiteen kentässä. Hallinnon tutkimus.

Howard-Grenville, J., Golden-Biddle, K., Irvin, J. \& Mao, J. (2011). Liminality as Cultural Process for Cultural Change. Organization Science, 22 (2), 522-539.

Johannson, Frans (2005). Medici-ilmiö: Huippuoivalluksia alojen välimaastossa. Helsinki: Talentum.

Julkunen, R. (2008). Uuden työn paradoksit. Keskusteluja 2000-luvun työprosess(e)ista. Tampere. Vastapaino.

Karsten, H. (1999). Relationship between organizational form and organizational memory: An investigation in a professional service organization. Journal of Organizational Computing and Electronic Commerce, Special Issue on Organizational Memory Systems. 9(2), 129-150.

Kouzes, J.M. \& Posner, B.Z. (1995). The Leadership Challenge. San Fransisco, CA: Jossey-Bass.

Kontinen, T. \& Järvinen, T. (2013). Kohti metodologista moninaisuutta? Seuranta- ja arviontitiedon ongelmat kansalaisjärjestöjen kehitysyhteistyön verkostoissa. Hallinnon tutkimus 32 (1), 40-54.

Kirjavainen, P. (1997). Strateginen oppiminen tietointensiivisessä organisaatiossa. Teoriaa luova tapaustutkimus oppimisesta kahden tietoyrityksen strategisessa kehityksessä. Turku: Turun kauppakorkeakoulun julkaisuja. Sarja A-2.

Laine, J. (2000). Toimialareseptin ja yritysparadigman muutos sekä sen vaikutus strategiseen muutokseen. Laadullinen ja historiallinen tapaustutkimus perheyrityksen siirtymisestä monialayhtymän osaksi. Jyväskylä: Jyväskylän 
Yliopisto, Jyväskylä Studies in Business and Economics, 1.

Lewin, K. (1958). Group Decisions and Social Change. Teoksessa: E.E. Maccobby, T.M. Newcomn ja E.L. Hartley (toim.). Readings in Social Psychology. New York: Holt, Rinehart \& Winston, 330-344.

Lewin, K. (1947) Field Theory in Social Sciences: Selected Theoretical Papers. New York: Harper \& Row.

Lewis, M., Haviland-Jones, J.M. \& Feldman Barret, L. (2008). Handbook of Emotions ( $3^{\text {rd }}$ Ed.). New York: The Guilford Press.

Lindsay, M.D. (2010). Organizational Liminality and Interstitial Creativity: The Fellowship of Power. Social Forces, 89(1), 163-184.

Lynes, M.A. \& Schwenk, C.R. (1992). Top Management, Strategy and Organizational Knowledge Structures. Journal of Management Studies. 29(2).

Hofstede, G. (2003). Culture's consequences. Comparing values, behaviours, institutions and organizations. USA: SAGE Publications.

Melander, A. (1997). Industrial Wisdom and Strategic Change. The Swedish Pulp and Paper Industry 1945-1990. Jönköping, Ruotsi: Jönköping University Jönköping International Business School.

Morgan, G. (2006). Images of Organization. Updated edition. Thousand Oaks: Sage.

Nonaka, I. \& Konno, N. (1998) The Concept of "Ba": Building a Foundation for Knowledge Creation. California Management Review, 40(3), 40-54.

Nyman, H. \& Hirkman, P. (2012). On the Nature of Supply Chain Management Projects and how to Manage Them. ECIS 2012 Proceedings. Paper 117. AlSeL. Saatavissa: http://aisel.aisnet.org/ ecis2012/117

Nohria, N. \& Eccles, R.G. (toim.) (1992). Networks and Organizations: structure, form, and action. Harvard Business School Press.

Powell, W.W. (1990) Neither market nor hierarchy: Network forms of organization. Research in Organisational Behavior, (12), 295-336.

Rojola, L. \& Laitinen, L. (1998). Keskusteluja performatiivisuudesta. Helsinki: SKS.

Rosen, M. (1988). You asked for it: Christmas at the Bosses Expense. Journal of Management Studies, 25, 463-480.

Seeck, H. (2008). Johtamisopit Suomessa. Taylorismista innovaatioteorioihin. Helsinki: Gaudeamus.

Schechner, R. (1986). Victor Turner's Last Adventure. Esipuhe teoksessa: Turner, V. The Antropology of Performance. New York: PAJ Publications.

Schein, E. (2006/1992) Organizational Culture and Leadership. $3^{\text {rd }}$ edition. USA: Jossey-Bass.
Schechner, R. (1988/2003). Performance Theory. London: Routledge.

Scott, W.R. \& Ruef, M. \& Mendel, P.J. \& Caronna, C.A. (2000) Institutional Change and Healthcare Organizations: From Professional Dominance to Magaged Care. Chicago: University of Chicago Press.

Sennett, R. (1998). The Corrosion of Character: The Personal Consequences of Work in the New Capitalism. London: W.W. Norton. [suom. 2002 Työn uusi järjestys. Miten uusi kapitalismi kuluttaa ihmisen luonnetta. Suom. Eine Kivinen, David Kivinen. Vastapaino. Tampere]

Singer, M. (1972). When a Great Tradition Modernizes. An Anthropological Approach to Indian Civilization. London: Pall Mall Press.

Spender, J.-C. (1989). Industry Recipes - An Enquiry into Nature and Sources of Managerial Judgment. Oxford, UK: Blackwell.

Spinuzzi, C. (2012). Working alone together: Coworking as emergent collaborative activity. Journal of Business and Technical Communication, 26(4), 399-441.

Tapscott, D. (2010). Syntynyt digiaikaan. Helsinki: WSOY. Tempest, S. (2007). 'Liminality'. Teoksessa: S.R. Clegg and J.R. Bailey (toim.), International Encyclopedia of Organizational Studies. Thousand Oaks: Sage, 821-824.

Tempest, S. \& Starkey, K. (2004). The effects of liminality on individual and organizational learning. Organization Studies, (25), 507-527.

Thorton, P., Ocasio W., Lounsbury, M. (2012). The Institutional Logics Perspective. A New Approach to Culture, Structure and Process. Oxford: Oxford University Press.

Thorton, P.H. \& W. Ocasio. (2008). Institutional logics. In: R. Greenwood \& C. Oliver \& K. SahlinAndersson \& R. Suddaby (eds.). The SAGE Handbook of Organizational Institutionalism. London: Sage, 99-129.

Tienari, J. \& Piekkari, R. (2011). Z ja epäjohtaminen. Hämeenlinna: Talentum.

Turner, V. (1969). The Ritual Process. Structure and AntiStructure. New York: Aldine de Gruyter.

Turner, V. (1974). Dramas, Fields, and Metaphors. Symbolic Action in Human Society. Ithaca, NY: Cornell University Press.

Turner, V. (1977). Variations of the theme of Liminality. In S. Moore \& Barbara G. Myerhoff (eds.): Secular Ritual, Assen, The Netherlands: Van Gorcu, 36-51.

Turner, V. (1979). Frame, Flow and Reflection: Ritual and Drama as Public Liminality. Japanese Journal of Religious Studies 6/4, 465-499. 


\section{VIITTEET}

Turner, V. (1985). On the Edge of the Bush. Anthropology as Experience. Tucson, Arizona: The University of Arizona Press.

Turner, W. \& Bruner, E.M. (1986). The Anthropology of Experience. Urbana: University of Illinois Press.

Turner, V. (1986). The Anthropology of Performance. New York: PAJ Publications.

Turner, V. (2007). Rituaali, Rakenne ja Communitas. Helsinki: Suomen Antropologinen Seura ja Summa.

Van Gennep, A. (1909/1960). Rites of passage. London: Routledge and Kegan Paul.

Viljanen, P. A. (2011). No Fear - johtaja kohtaa digicowboyt. WSOYpro Oy. Helsinki.

Weick, K.E. \& Quinn, R.E. (1999). Organizational Change and Development. Annual Review of Psychology (50), 361-386.
1 Tämän artikkeli on kirjoitettu Liminarikonsortion tutkimushankkeessa "Työ ja johtajuus liminaalitilassa" (2012-2013). Hankkeessa tutkitaan taidealojen, osuuskuntien, kansalaisjärjestöjen ja ohjelmistokehitysprojektien muuttuvaa työtä ja niihin nivoutuvia uudenlaisia johtajuuden tapoja (ks. Kontinen \& Järvinen 2013; Houni, Ansio, Järvinen 2013 tulossa; Nyman \& Hirkman 2012). Kiitämme rahallisesta tuesta Tekesiä (projektit 4048740490/11). Kirjoittajat ovat tekijöiden sopimassa järjestyksessä; artikkelin sisällöstä vastaavat pääasiassa Kontinen ja Houni. Kirjoittajat kiittävät kommenteista tutkimusryhmän jäseniä: Heli Ansio, Piia Hirkman ja Henrik Nyman.

2 Y-sukupolvi (1982 jälkeen syntyneet) ja myöhemmin Z-sukupolvi (1998 jälkeen syntyneet) on muuttamassa johtamiskäytäntöjä aikaisempiin sukupolviin verrattuna. Näiden nettisukupolvien sitoutuminen on kevyempää - he ovat kiinnostuneita, avoimia ja monikanavaisia. Y-sukupolvi opiskelee, tulee työelämään ja osallistuu yhteiskunnan rakentamiseen lisääntyvässä määrin. Y-sukupolven johtamisessa ja uuden työn johtamisessa saattaa olla samoja elementtejä innovatiivisuuden kannalta.

3 Liminaalisuus on yksi keskeisistä käsitteistä esimerkiksi performance studies -tutkimussuuntauksessa, naistutkimuksessa ja psykologian tietyissä suuntauksissa (esim. Schechner 2003, Butler 2006). 